\title{
The effects of sulfide stress cracking on the mechanical properties and intergranular cracking of P110 casing steel in sour environments
}

\author{
Hou Duo, Zeng Dezhi *, Shi Taihe, Zhang Zhi and Deng Wenliang \\ State Key Laboratory of Oil and Gas Reservoir Geology and Exploitation, Southwest Petroleum University, Chengdu, \\ Sichuan 610500, China \\ (C) China University of Petroleum (Beijing) and Springer-Verlag Berlin Heidelberg 2013
}

\begin{abstract}
Variation and degradation of P-110 casing steel mechanical properties, due to sulfide stress cracking (SSC) in sour environments, was investigated using tensile and impact tests. These tests were carried out on specimens, which were pretreated under the following conditions for 168 hours: temperature, $60{ }^{\circ} \mathrm{C}$; pressure, $10 \mathrm{MPa} ; \mathrm{H}_{2} \mathrm{~S}$ partial pressure, $1 \mathrm{MPa}$ and $\mathrm{CO}_{2}$ partial pressure, $1 \mathrm{MPa}$; preload stress, $80 \%$ of the yield strength $\left(\sigma_{\mathrm{s}}\right)$; medium, simulated formation water. The reduction in tensile and impact strengths for P-110 casing specimens in corrosive environments were $28 \%$ and $54 \%$, respectively. The surface morphology analysis indicated that surface damage and uniform plastic deformation occurred as a result of strain aging. Impact toughness of the casing decreased significantly and intergranular cracking occurred when specimens were maintained at a high stress level of $85 \% \sigma_{\mathrm{s}}$.
\end{abstract}

Key words: Acidic solutions, high-temperature corrosion, hydrogen embrittlement, intergranular corrosion, sulfide stress cracking

\section{Introduction}

Steels react with hydrogen sulfide, forming metal sulfides and atomic hydrogen as corrosion byproducts. The atomic hydrogen can diffuse into the metal matrix, creating hydrogen embrittlement and subsequent cracking. This is termed sulfide stress cracking (SSC) and is more severe at low $\mathrm{pH}$ values.

Sulfide stress cracking is becoming a key issue due to high levels of $\mathrm{H}_{2} \mathrm{~S}$ and $\mathrm{CO}_{2}$ in new natural gas reservoirs (Carneiro et al, 2003; Kermani et al, 2006).

Furthermore, severe working conditions, to which drilling equipment is exposed in reservoirs, require high grade steels capable of resisting SSC and withstanding high mechanical loads under conditions that encourage hydrogen embrittlement (HE) (Zhao and Yang, 2003; Zhao et al, 2003; Crabtree and Gavin, 2005).

Therefore, it is essential to evaluate different methods for the determination of the ability of a material to resist cracking in sour environments (Grabtree and Gavin, 2005). The National Association of Corrosion Engineers, NACE International, adopts different methods for evaluating a material's susceptibility to stress corrosion cracking (SCC) in a wet $\mathrm{H}_{2} \mathrm{~S}$ environment. Sulfide stress cracking (SSC) is a form of hydrogen embrittlement which is a cathodic cracking mechanism. It should not be confused with the term stress

*Corresponding author. email: dragon-duo@hotmail.com Received December 17, 2012 corrosion cracking (SCC) which is an anodic cracking mechanism.

Specifically, testing methods using the bend specimen geometry described in the ASTM standards (ASTM International, 1999) and the double cantilever beam (DCB) test described in the NACE standards (NACE International, 2005) are used in design/fitness for service evaluating and for determining material qualifications and specifications (Hay, 2001; Cravero et al, 2009). Gelder et al (1987) investigated the susceptibility of stainless steel to SSC in sour environments containing $\mathrm{H}_{2} \mathrm{~S}, \mathrm{CO}_{2}$ and chloride using slow strain rate testing (SSRT). Albarran et al (1999) studied the effects of heat-treatments on pipeline steel resistant to SSC, using linear elastic fracture mechanics (LEFM) on standard impact specimens. Several researchers (Ritchie et al, 1978; Toribio et al, 1993; Thompson et al, 2007) investigated the main variables that affect SSC of steel in sour environments. Although the DCB test is standardized, it is widely known that using the NACE TM0177 method D (DCB test) testing procedure can affect the value obtained for the fracture toughness $\left(K_{\mathrm{IC}}\right)$. In this procedure, variables such as the height of the wedge (the initially applied $K_{\mathrm{I}}$ ) and the $\mathrm{pH}$ of the solution can also affect the final results (Mack et al, 2000; Cravero et al, 2010).

There is an urgent need to develop better methods for evaluating the mechanical properties of metals after exposure to aqueous $\mathrm{H}_{2} \mathrm{~S} / \mathrm{CO}_{2}$ environments with high $\mathrm{H}_{2} \mathrm{~S}$ partial 
pressures. Several researchers (Srinivasan and Kane, 1996; Srinivasan and Tebbal, 1998; Nesic et al, 2005; Smith and Joosten, 2006) discussed that there are currently no generally accepted prediction algorithms for any form of $\mathrm{H}_{2} \mathrm{~S}$ corrosion. There are still many uncertainties about the corrosive reactions that lead to pitting, which is the most common mode of sour service equipment failure. Zhang et al (2011) found that the hydrogen sulfide content in some wells exceeded 10 vol.\% in the Sichuan sour gas fields in China. In these wells, the partial pressure of $\mathrm{H}_{2} \mathrm{~S}$ reached about $3 \mathrm{MPa}$ and the temperature was $95-115^{\circ} \mathrm{C}$. Since no practical experience had been available for the corrosion of carbon steels under these extreme conditions, it is difficult to design effective evaluation methods for the corrosion-resistance of materials. Zhang et al (2011) studied the ability of sulfur to accelerate the corrosion of carbon steel in wet $\mathrm{H}_{2} \mathrm{~S}$ environments, showing that sulfur severely accelerated SSC. However, the methods discussed above cannot be used to evaluate the variations and degradations of mechanical properties of steel equipment and casings in sour wells, and cannot suggest the strength criteria as a standard. For these reasons, it is important to learn about hydrogen embrittlement, study the hydrogen concentration and evaluate the effects of material properties in order to develop new testing methods and identify proper strength criteria for well casings in sour environments.

To date, most research on hydrogen embrittlement has investigated absorption of hydrogen into line pipe steels and susceptibility of these steels to hydrogen induced cracking (HIC) in solutions saturated with high pressure $\mathrm{H}_{2} \mathrm{~S}$ and $\mathrm{CO}_{2}$. Eliaz et al (2002) reported that steel's susceptibility to HIC and its absorbed hydrogen content increased as the partial pressures of $\mathrm{H}_{2} \mathrm{~S}$ and $\mathrm{CO}_{2}$ increased. Several researchers (Michler and Naumann, 2008; Woodtli and Kieselbach, 2000) reported that the susceptibility of pipeline steels to HIC in $\mathrm{NaCl}$ solutions saturated with high pressure of $\mathrm{H}_{2} \mathrm{~S}$ depended on the hydrogen permeability of steel. Many studies (Shimada et al, 2002; Otegui et al, 2009; Stoll and Wilkinson, 2012) have also investigated the conditions that make metals more prone to intergranular cracking and have assessed the deformation mechanisms of hydrogen embrittlement induced by temperature susceptibility. In addition, other scientists (Venegas et al, 2011; Pal et al, 2012) have reported the mechanisms associated with intergranular corrosion and sulfide cracking, but there is not much information about SSC susceptibility in V-notched specimens and loss in mechanical properties caused by hydrogen damage in sour environments.

In this study, we used P-110 casing steel specimens to examine loss in tensile and impact strengths under sour conditions. Using a high temperature high pressure (HTHP) autoclave (homemade, $70 \mathrm{MPa}, 300{ }^{\circ} \mathrm{C}$ ), a loading fixture for tensile specimens, and a loading fixture for bend specimens, we measured the tensile and impact properties of P-110 casing specimens before and after they were exposed to the sour environments: temperature at $60{ }^{\circ} \mathrm{C}$; total pressure, 10 $\mathrm{MPa} ; \mathrm{H}_{2} \mathrm{~S}$ partial pressure $1 \mathrm{MPa}$ and $\mathrm{CO}_{2}$ partial pressure 2 $\mathrm{MPa}$; preload stress, $80 \%$ of the yield strength $\left(\sigma_{\mathrm{s}}\right)$ for 168 hours.

\section{Experimental}

\subsection{Materials and corrosive medium}

Standard tensile test specimens with an outside diameter of $6.35 \mathrm{~mm}$ were machined from P-110 casing (an outside diameter of $177.8 \mathrm{~mm}$, a wall thickness of $12.65 \mathrm{~mm}$, and a yield strength $\left(\sigma_{\mathrm{s}}\right)$ of $110 \mathrm{ksi}(758 \mathrm{MPa})$ ) according to the NACE TM0177 method, as shown in Fig. 1.

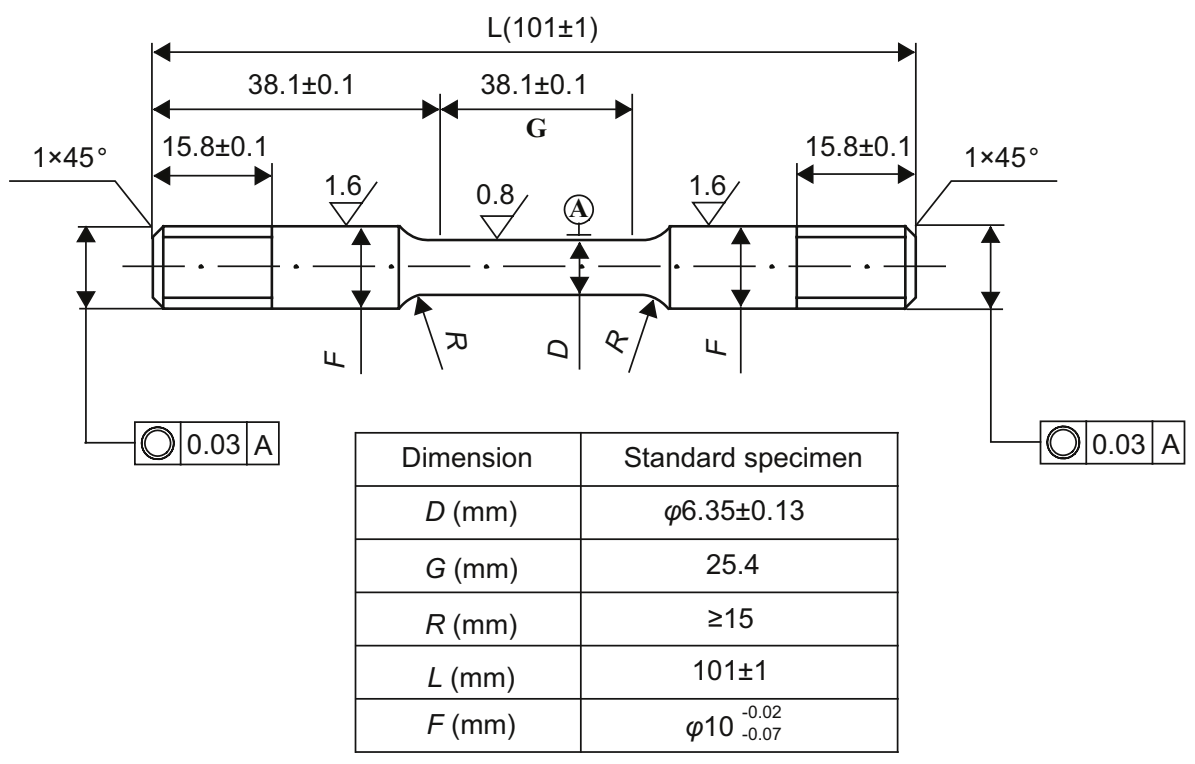

Fig. 1 Dimensions of standard tensile test specimens

Sub-size specimens for the Charpy impact test were machined from P-110 casing according to the ASTM E399 and ASTM A370 standards. The dimensions of these sub- size specimens were $10 \mathrm{~mm} \times 5 \mathrm{~mm} \times 55 \mathrm{~mm}$, containing a 2 mm-deep V notch. The chemical composition of P-110 casing is listed in Table 1. 
Simulated water was prepared to match as closely as possible the analysis of formation water obtained from the Puguang gas-field in Sichuan Province, China and its properties are listed in Table 2. The corrosive medium was saturated with $\mathrm{H}_{2} \mathrm{~S}$ (99.5\% pure) and $\mathrm{CO}_{2}$ (99.8\% pure), and $\mathrm{N}_{2}\left(99.9 \%\right.$ pure) was used for pressurization, $\mathrm{H}_{2}$ and $\mathrm{CH}_{4}$ is not used in this test.

Table 1 Chemical composition of P-110 casing

\begin{tabular}{cccccccccc}
\hline & \multicolumn{8}{c}{ Chemical composition, wt\% } \\
\cline { 2 - 9 } Steel grade & C & Si & Mn & P & S & Cr & Mo & Others \\
\hline P110 & 0.32 & 0.34 & 0.59 & 0.013 & 0.006 & 2.42 & 0.85 & Ni \\
\hline
\end{tabular}

Table 2 Properties of simulated formation water

\begin{tabular}{|c|c|c|c|c|c|c|c|c|c|}
\hline \multicolumn{7}{|c|}{ Composition, $g / L$} & \multirow{2}{*}{$\begin{array}{c}\text { Density } \\
\mathrm{g} / \mathrm{cm}^{3}\end{array}$} & \multirow{2}{*}{$\begin{array}{c}\mathrm{pH} \\
\text { value }\end{array}$} & \multirow{2}{*}{$\begin{array}{c}\text { Salinity } \\
\mathrm{g} / \mathrm{L}\end{array}$} \\
\hline $\mathrm{Na}^{+}$ & $\mathrm{K}^{+}$ & $\mathrm{Ca}^{2+}$ & $\mathrm{Mg}^{2+}$ & $\mathrm{Cl}^{-}$ & $\mathrm{SO}_{4}{ }^{2-}$ & $\mathrm{HCO}_{3}^{-}$ & & & \\
\hline 59.0 & 10.0 & 11.4 & 2.43 & 126.5 & 0.71 & 0.71 & 0.996 & 5.38 & 210.8 \\
\hline
\end{tabular}

\subsection{Tensile testing}

The tensile specimen was mounted onto a specialized loading fixture for tensile specimens (1), shown in Fig. 2. With an MTS-810 tensile testing machine (MTS Corporation, Minneapolis, USA) a preload was applied on the tensile specimen until the stress and strain of the specimen reached $606 \mathrm{MPa}\left(80 \% \sigma_{\mathrm{s}}\right)$ and $0.28 \%$, respectively. The stress-strain curve of a tensile specimen is shown in Fig. 3. Then, the nut number was screwed down to maintain a constant load $\left(80 \% \sigma_{\mathrm{s}}\right)$ on the specimen so that the stress and strain did not change during the corrosion test. The assembly of the loading fixture (1) with the tensile specimen were removed from the testing machine and then immediately placed in a 6-liter autoclave, shown in Fig. 4. In these stress corrosion tests, the specimens were immersed in the simulated formation water for 168 hours at $60{ }^{\circ} \mathrm{C}$ and $10 \mathrm{MPa}$. Moreover, the $\mathrm{H}_{2} \mathrm{~S}$ and $\mathrm{CO}_{2}$ partial pressures were kept at 1 and $2 \mathrm{MPa}$, respectively; and the water flow rate was controlled at $2 \mathrm{~m} / \mathrm{s}$. Following exposure to the sour environment, the specimens were

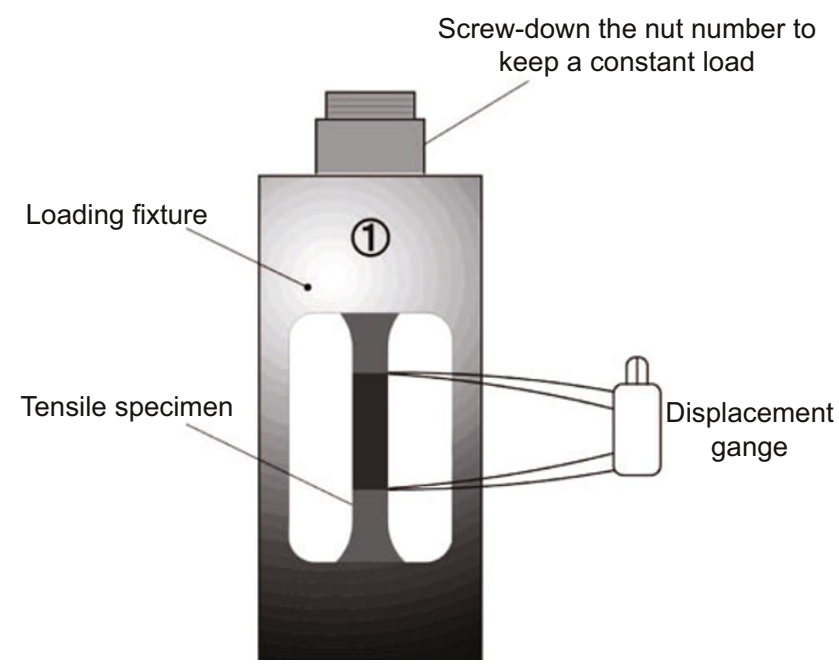

Fig. 2 Assembly of the loading fixture for tensile specimens

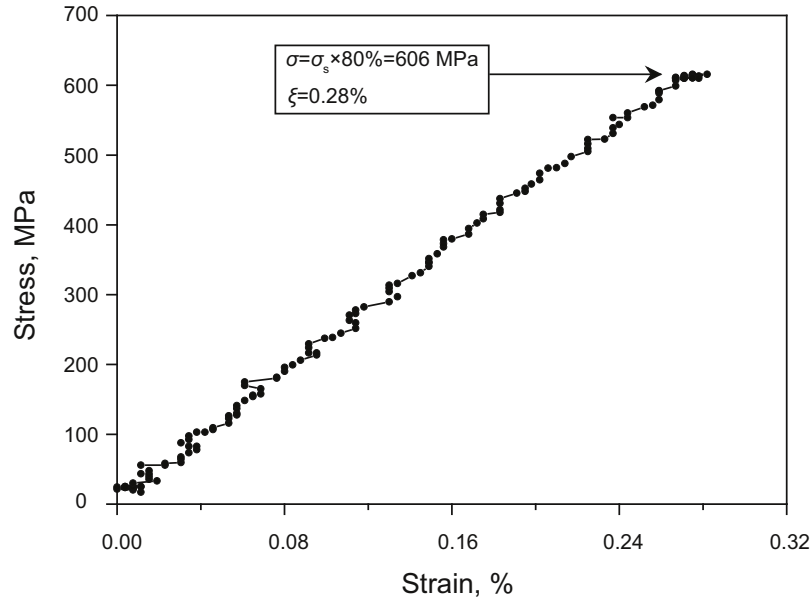

Fig. 3 Stress-strain curve of the tensile specimen during preloading

removed from the loading fixture and then the tensile testing was conducted on these specimens. All evaluations were repeated three times and averaged.

This autoclave was designed and constructed to allow the introduction of multiphase flow. The maximum operating pressure and temperature were $70 \mathrm{MPa}$ and $300{ }^{\circ} \mathrm{C}$. The loading fixture and the autoclave were made of Hastelloy $\mathrm{C}-276$. The difference in the thermal expansion coefficient between Hastelloy C-276 and carbon steel was only 1.2-1.8 $\mu \mathrm{m} /\left(\mathrm{m} \cdot{ }^{\circ} \mathrm{C}\right)\left(\right.$ at $\left.20-200{ }^{\circ} \mathrm{C}\right)$, and the strain of the P-110 casing specimen was $0.28 \%(0.07 \mathrm{~mm})$. Therefore, the fixture was able to maintain a constant load on the specimen during exposure to a sour environment for 168 hours.

For comparison, four groups of tensile specimens pretreated at different conditions were prepared and used to conduct following examinations. Tensile specimens without any pretreatment were designated Specimens A and Specimens B were obtained after the tensile specimens were exposed to air at $25{ }^{\circ} \mathrm{C}$ for 168 hours with a preload of $80 \% \sigma_{\mathrm{s}}$. The specimens which had been exposed to the sour environment for 168 hours with a preload of $80 \% \sigma_{s}$, were named Specimens $\mathrm{C}$ (the $\mathrm{pH}$ value of the formation water was 5.38) and Specimens D (the $\mathrm{pH}$ value of the formation water was adjusted to 3 using $\mathrm{CH}_{3} \mathrm{COOH}$ ).

The true stress-strain curves of each group of specimens were drawn to analyze the results of the tensile test. The hardening index of each specimen was calculated from Eq. (1). The strain energy density was calculated from Eq. (2), which represents the total mechanical energy of the P-110 casing specimen consumed until failure, and numerically equals the area under the stress-strain curve from zero to fracture point. Fracture toughness $\left(K_{\mathrm{IC}}\right)$ was calculated from Eq. (3).

$$
\begin{gathered}
n=\frac{N \sum_{i=1}^{N} x_{i} y_{i}-\sum_{i=1}^{N} x_{i} \sum_{i=1}^{N} y_{i}}{N \sum_{i=1}^{N} x_{i}^{2}-\left(\sum_{i=1}^{N} x_{i}\right)^{2}} \\
U^{*}=\frac{1}{V} \int P \mathrm{~d} L=\int_{0}^{L} \frac{P}{A_{0}} \frac{\mathrm{d} L}{L_{0}}=\int_{0}^{\varepsilon} \sigma \mathrm{d} \varepsilon
\end{gathered}
$$




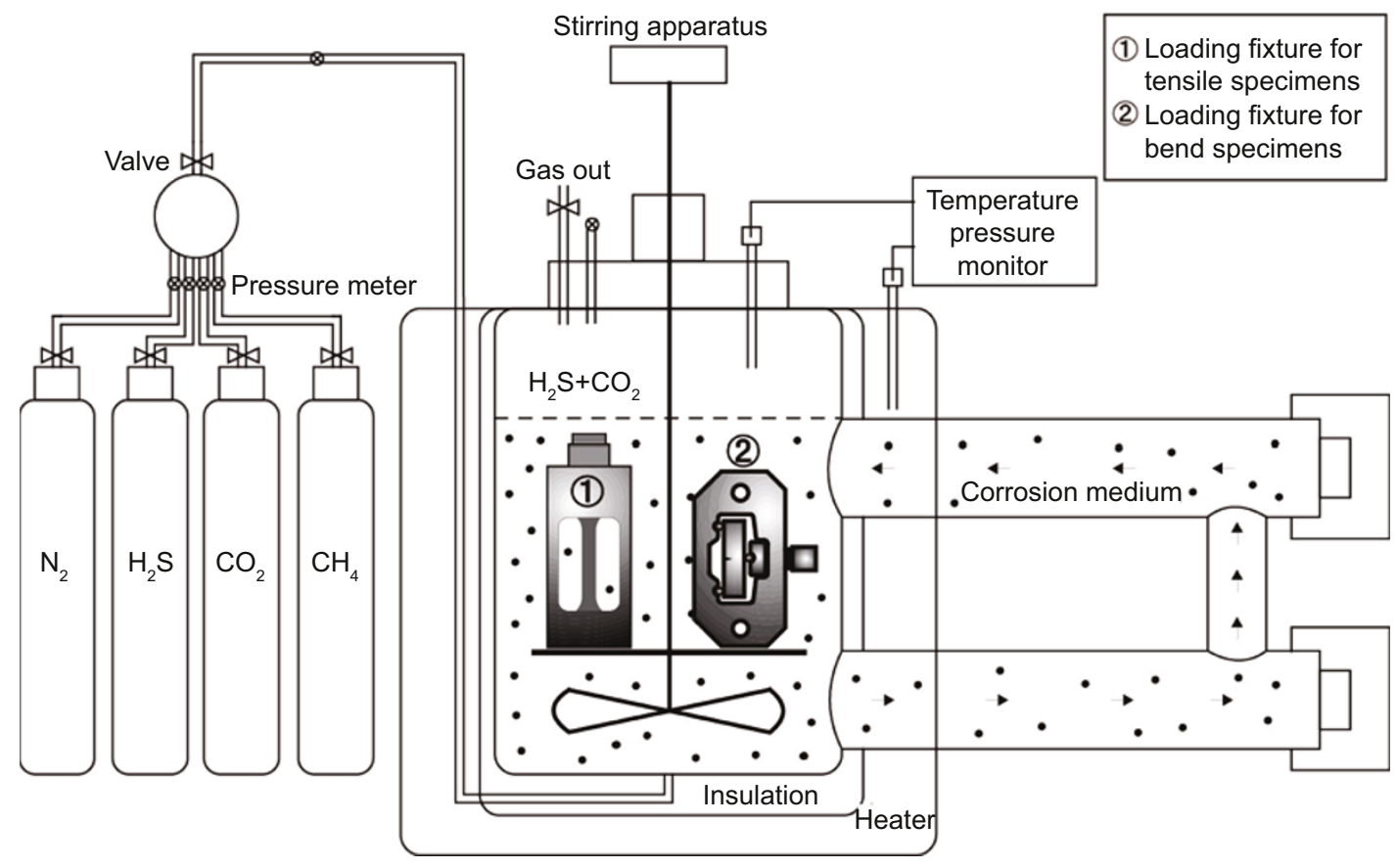

Fig. 4 Schematic of the autoclave for $\mathrm{H}_{2} \mathrm{~S}$ and $\mathrm{CO}_{2}$ corrosion tests

$$
K_{\mathrm{IC}}=F\left(\frac{d_{\mathrm{a}}}{d_{\mathrm{F}}}\right) \frac{4 P_{\mathrm{F}}}{\pi\left(d_{\mathrm{F}}^{2}-d_{\mathrm{a}}^{2}\right)} \sqrt{\frac{\pi}{2} d_{a}}
$$

with

$$
\begin{aligned}
& x_{i}=\ln e \\
& y_{i}=\ln s \\
& F\left(\frac{d_{\mathrm{a}}}{d_{\mathrm{F}}}\right)=\sqrt{\left(1-\frac{d_{\mathrm{a}}}{d_{\mathrm{F}}}\right)} \frac{2}{\pi}\left[1+\frac{1}{2}\left(\frac{d_{\mathrm{a}}}{d_{\mathrm{F}}}\right)-\frac{5}{8}\left(\frac{d_{\mathrm{a}}}{d_{\mathrm{F}}}\right)^{2}+0.421\left(\frac{d_{\mathrm{a}}}{d_{\mathrm{F}}}\right)^{3}\right]
\end{aligned}
$$

where $n$ is the hardening index; $N$ is the total number of measurement points; $s$ is the true stress, $s=\sigma^{*}(1+\varepsilon) ; e$ is the true plastic strain, $e=\ln (1+\varepsilon) ; \varepsilon$ is the strain, dimensionless; $U^{*}$ is the strain energy density, $\mathrm{J} / \mathrm{m}^{3} ; V$ is the specimen volume, $\mathrm{m}^{3} ; P_{\mathrm{F}}$ is the critical load of crack propagation, determined by the standard method outlined in ASTM E399, $\mathrm{kN} ; A_{0}$ is the cross-sectional area of the specimen, $\mathrm{m}^{2} ; L$ is the elongation of the specimen, $\mathrm{m} ; \sigma$ is the stress, MPa; $d_{\mathrm{a}}$ and $d_{\mathrm{F}}$ are the diameter of the fibrous zone and the cross-sectional diameter of the fractured neck, respectively, as shown in Fig. 5; $P_{\mathrm{F}}$ is the critical load, determined by the standard method outlined in ASTM E399.

\subsection{Three-point bend testing and impact testing}

The procedure for installing the Charpy impact specimen on the three-point bend fixture (2) is shown in Fig. 6. The load imposed on the specimen was adjusted by the displacement of the V-notch, which was controlled by the nut number. A dial indicator was mounted to measure the specimen displacement and then the stress applied at the crack tip of the specimen could be calculated by finite element analysis. The stress at

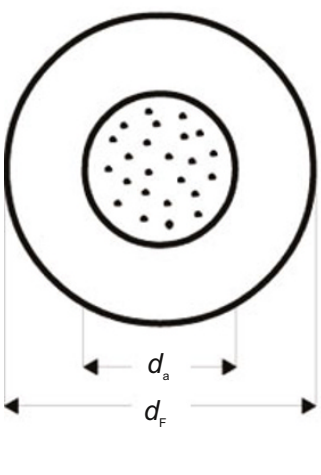

(a)

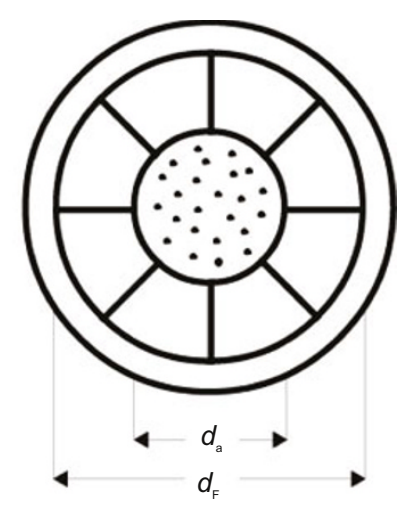

(b)
Fig. 5 The necked section (a) and the top view of the fracture plane (b) of the tensile specimen

the crack tip reached $80 \% \sigma_{\mathrm{s}}$ when the displacement of the $\mathrm{V}$-notch was $0.12 \mathrm{~mm}$, which can be seen from the stressdisplacement curve in Fig. 7.

The three-point bend testing was also conducted at 60 ${ }^{\circ} \mathrm{C}$ and $10 \mathrm{MPa}$ in the autoclave for 168 hours and the stress imposed on the specimen was maintained at $80 \% \sigma_{\mathrm{s}}$. In this autoclave, the $\mathrm{H}_{2} \mathrm{~S}$ and $\mathrm{CO}_{2}$ partial pressures were kept at 1 and $2 \mathrm{MPa}$, respectively; the water flow rate was controlled at $2 \mathrm{~m} / \mathrm{s}$; and the $\mathrm{pH}$ value of the corrosive medium was 5.38. After 168-hour exposure, the sub-size specimen, named as Sub-size specimens E, was removed from the threepoint bend fixture and the impact testing was immediately performed at room temperature to obtain crack propagation force $F_{\mathrm{Q}}$, shown in Fig. 8. For comparison, other sub-size specimens without any pretreatment, named as Sub-size specimens $\mathrm{F}$, was also tested at $25^{\circ} \mathrm{C}$. All evaluations were repeated for three times and averaged. 


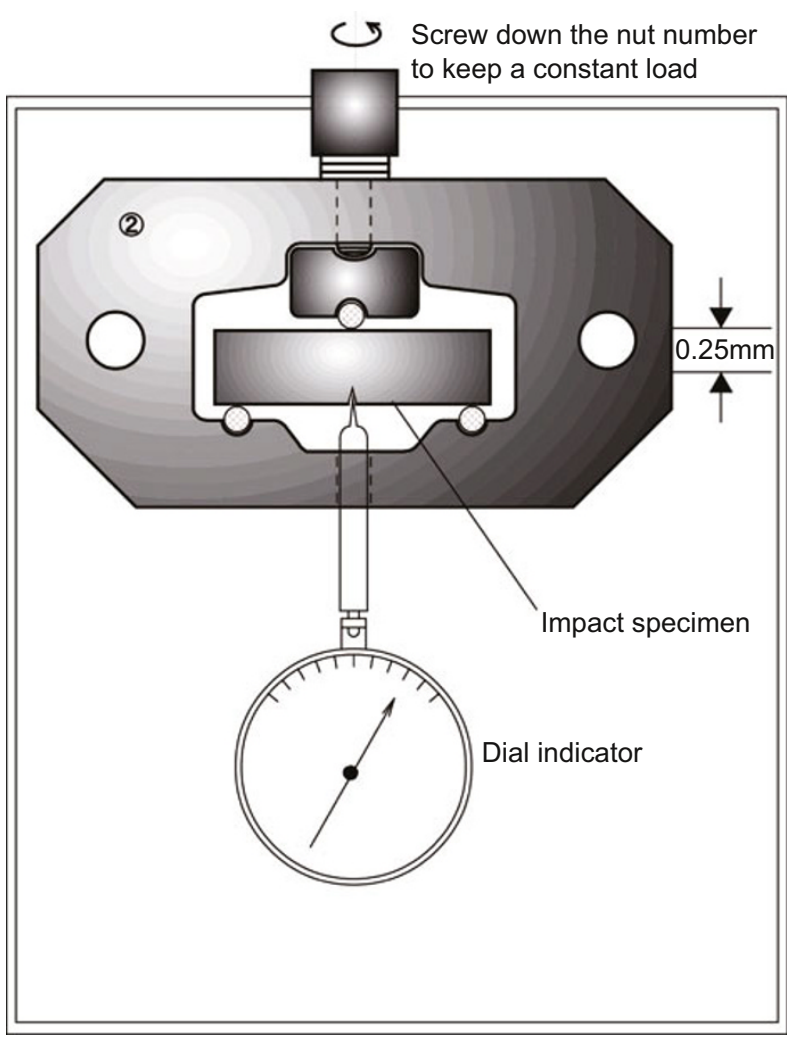

Fig. 6 Assembly of three-point bend test for the sub-size specimens

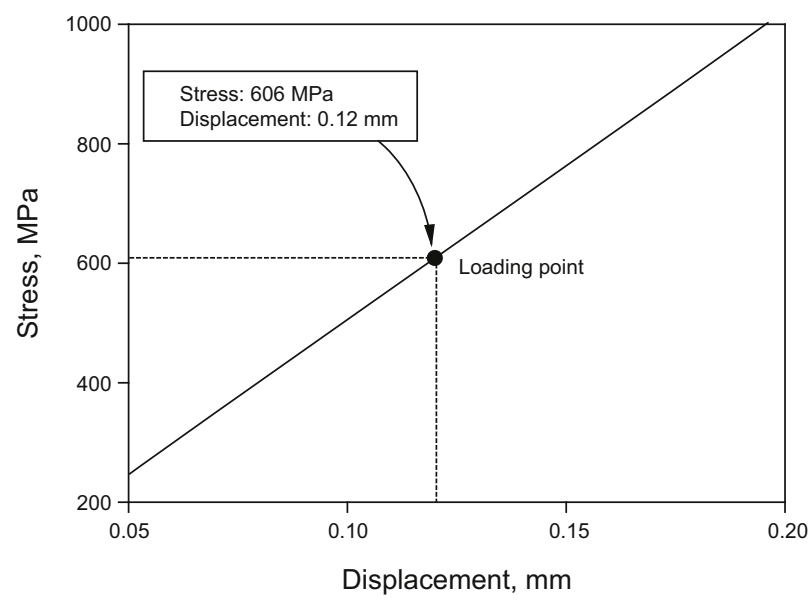

Fig. 7 Stress-displacement curve and preloading point

The P-110 casing steel impact specimens were exposed to sour environments and simultaneously underwent threepoint bending stress. After 168 hours, the specimens were taken from the autoclave and immediately impact tests were conducted at room temperature. The value of $K_{\mathrm{Q}}$ was calculated from Eq. (4).

$$
K_{\mathrm{Q}}=\frac{P_{\mathrm{Q}} S}{\sqrt{B B_{\mathrm{N}}} W^{\frac{3}{2}}} f\left(\frac{a}{W}\right)
$$

with

$$
\begin{aligned}
& f\left(\frac{a}{W}\right)= \\
& 3 \sqrt{\left(\frac{a}{W}\right) \frac{1.99-\left(\frac{a}{W}\right)\left(1-\frac{a}{W}\right)\left[2.15-3.93 \frac{a}{W}+2.7\left(\frac{a}{W}\right)^{2}\right]}{2\left(1-2 \frac{a}{W}\right)\left(1-\frac{a}{W}\right)^{\frac{3}{2}}}}
\end{aligned}
$$

where $P_{\mathrm{Q}}$ is the crack extension force; $B$ is the specimen thickness; $B_{\mathrm{N}}$ is the specimen thickness between the roots of the side grooves; $W$ is the specimen width; $S$ is the span of the specimen, $S=4 W ; a$ is the crack size.

The value of $K_{\mathrm{Q}}$ was equal to the fracture toughness $\left(K_{\mathrm{IC}}\right)$ when the $\left(B, B_{N}, W-a\right) \geq 2.5\left(\frac{K_{Q}}{\sigma_{y}}\right)^{2}$. Otherwise, the test is not a valid $K_{\mathrm{IC}}$ test.

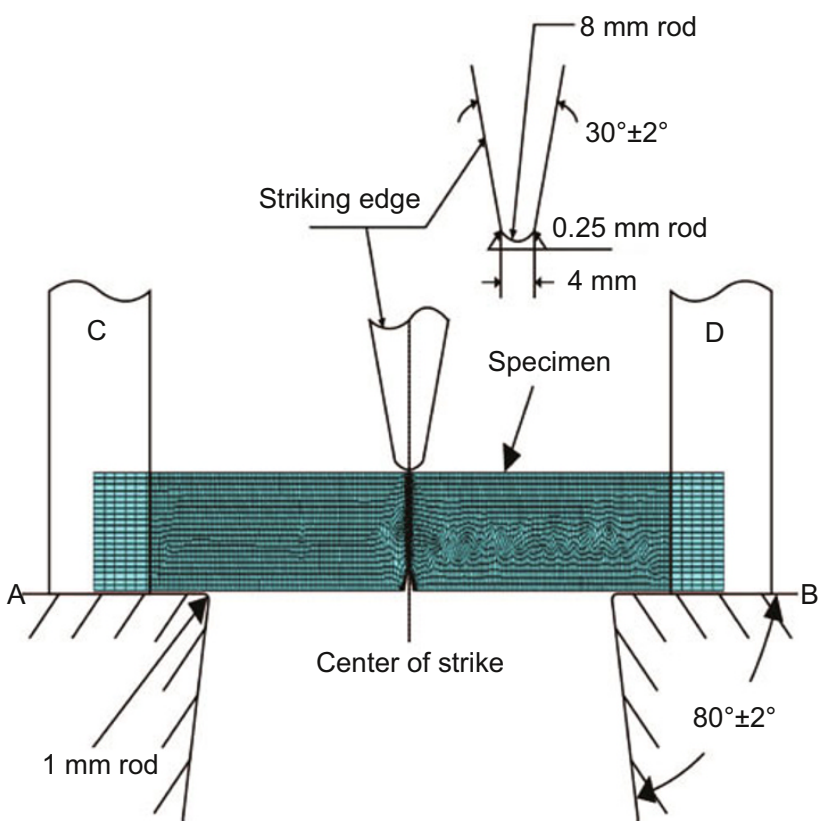

Fig. 8 The impact test for measurement of the crack extension force $\left(F_{\mathrm{Q}}\right)$ of sub-size specimens $\mathrm{E}$ and $\mathrm{F}$

\section{Results and discussion}

\subsection{Loss of mechanical properties and hydrogen damage}

Mechanical properties of tensile specimens exposed to different conditions are listed in Table 3.

The results of Specimens B indicate that the elastic deformation of the casing specimen caused by stress was recoverable when the stress was removed, and its tensile strength and yield strength actually increased due to strain hardening. The results of tensile tests performed on Specimens C and D were stable and reliable. From these tests, we found that for the specimens exposed to sour environments at $60{ }^{\circ} \mathrm{C}$ and $10 \mathrm{MPa}$ with a preload of $80 \% \sigma_{\mathrm{s}}$, the deformation of the casing specimens cannot be recovered, resulting in significant losses in mechanical properties. Furthermore, these results show that the fracture toughness drastically reduced to $50 \mathrm{MPa} \cdot \mathrm{m}^{1 / 2}$, this is mainly due to 
Table 3 Tensile properties of tensile specimens exposed to different environments

\begin{tabular}{|c|c|c|c|c|c|c|c|c|}
\hline Specimens & $\begin{array}{c}\text { Yield stress } \\
\sigma_{\mathrm{b}}, \mathrm{MPa}\end{array}$ & $\begin{array}{c}\text { Tensile } \\
\text { stress } \\
\sigma_{\mathrm{s}}, \mathrm{MPa}\end{array}$ & $\begin{array}{c}\text { Elongation } \\
\delta, \%\end{array}$ & $\begin{array}{c}\text { Reduction } \\
\text { of area } \\
\psi, \%\end{array}$ & $\begin{array}{c}\text { Young's } \\
\text { modulus } \\
E, \mathrm{GPa}\end{array}$ & $\begin{array}{c}\text { Hardening index } \\
n\end{array}$ & $\begin{array}{c}\text { Fracture } \\
\text { toughness } \\
K_{\mathrm{IC}}, \mathrm{MPa} \cdot \mathrm{m}^{1 / 2}\end{array}$ & $\begin{array}{c}\text { Strain energy } \\
\text { density } \\
V_{\varepsilon}, \mathrm{J} / \mathrm{m}^{3}\end{array}$ \\
\hline A & 989 & 936 & 23.6 & 67.2 & 215 & 0.096 & 85.4 & 195 \\
\hline B & 1030 & 966 & 20.9 & 62.2 & 220 & 0.092 & 79.8 & 203 \\
\hline $\mathrm{C}$ & 943 & 889 & 21.9 & 66.5 & 208 & 0.092 & 50.1 & 180 \\
\hline D & 950 & 903 & 22.0 & 66.5 & 199 & 0.092 & 50.0 & 181 \\
\hline
\end{tabular}

corrosion by $\mathrm{H}_{2} \mathrm{~S}$ and $\mathrm{CO}_{2}$. The tensile specimens examined in this study represented two different types of strain aging: ordinary strain aging occurred in Specimens B, which could be recovered; special strain aging caused by corrosion due to $\mathrm{H}_{2} \mathrm{~S}$ and $\mathrm{CO}_{2}$, which occurred in Specimens $\mathrm{C}$ and $\mathrm{D}$ and could not be recovered. This special strain aging due to $\mathrm{H}_{2} \mathrm{~S}$ and $\mathrm{CO}_{2}$ corrosion also led to decays in the strength, ductility, and toughness of the casing specimens. The reduction in tensile strength, yield strength and fracture toughness of the casing steel specimens can be attributed to the degradation of the steel mechanical properties caused by combined effects of the sour environment and the stress state. This shows that the casing mechanical properties will significantly reduce in wellhead and bottom conditions due to the combined corrosive effect. Compared with Specimens A, the true stressstrain curves of Specimens C and D have moved down, as shown in Fig. 9. It is found that the strain energy density $\left(V_{\varepsilon}\right)$ of Specimens B calculated by integrating increased by $8.6 \mathrm{~J} /$ $\mathrm{m}^{3}$, while those of Specimens $\mathrm{C}$ and D decreased by $15.0 \mathrm{~J} /$ $\mathrm{m}^{3}$. Similarly, Fig. 9 shows that the strain energy per unit volume of the casing specimens changed after the casing was placed in service in sour well conditions. The specimens exposed to air (Specimens B) show an increase in strength and a decrease in plasticity. Because of strain hardening induced by preloading, local plastic deformation (dislocation movement) occurred, the grain size increased, and the accumulation of dislocations increased the local strength (the local strength increased due to the cumulative effect of grain growth and dislocation accumulation). For Specimens $\mathrm{C}$ and $\mathrm{D}$, the strength and plasticity decreased due to $\mathrm{H}_{2} \mathrm{~S}$, $\mathrm{CO}_{2}$ contained in the corrosive medium. The strain energy loss would occur in sour environments and the loss energy is equivalent to hydrogen surface damage induced by SSC.

The surfaces of specimens $\mathrm{C}$ and $\mathrm{D}$ were investigated with a scanning electron microscope (Quanta 450, American FEI) and a large number of narrow cracks and other signs of corrosion were observed to have formed due to the combined effects associated with the $\mathrm{H}_{2} \mathrm{~S}$ and $\mathrm{CO}_{2}$ corrosion medium. The corrosion was accelerated at local surfaces because of combined actions of stress concentration and pitting. The specimens showed plastic deformation, increased lengths, and reduced outer diameters, as shown in Fig. 10. The narrow cracks formed on the specimen surface had a width of 100 $\mu \mathrm{m}$ and a depth of 80-120 $\mu \mathrm{m}$.

The tensile fracture of Specimens A, shown in Fig. 11(a) and Fig. 11(b), represented a fibrous fracture that had many secondary cracks. Fig. 11(c) and Fig. 11(d) show the tensile

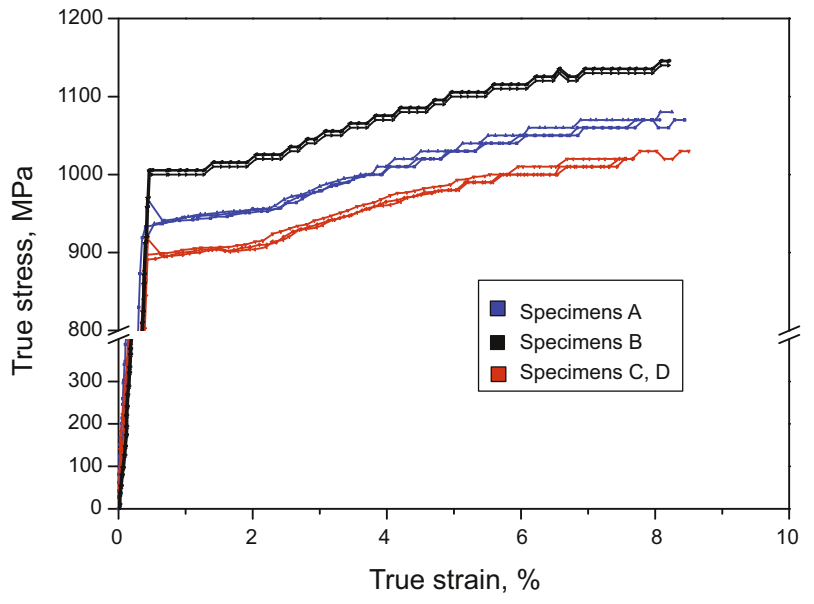

Fig. 9 True stress-strain curves of specimens A, B, C and D

fracture of Specimens C, which had a smaller cross-sectional area than Specimens A and a large number of cavity-like structures. The differences between Specimens A and C are as follows: the cross-sectional area of Specimens C decreased and while the crystalline area increased. Specimens A showed greater plastic deformation after yielding, and then necking occurred followed by fracturing. Specimens C showed creep behavior and dislocation gliding during the stress corrosion test, causing no significant yield platform or deformation. The total elongation of Specimens $C$ was less than that of Specimens A, which was caused by hydrogen permeation and hydrogen gathering at local defects in Specimens C. An increase in space between crystals observed in Specimens $\mathrm{C}$ resulted in plastic deformation that occurred at inclusions and grain boundaries. Slippage then occurred along the closepacked (111) direction in the body-centered cubic (BCC) crystal structure. In the process of tensile test, shear stresses acted in the directions of planes (111) and (111), which caused necking and then a reduction in dislocation glide. Hydrogen permeation led to surface damage, which allowed hydrogen atoms to permeate even further. The cavity-like structures continued to expand since the stress kept increasing during the tensile testing. Eventually, large cavity-like structures were formed, resulting in decreases in strength, ductility, and toughness of the P-110 casing steel specimens.

The experimental results show that the combined action of sour environment and applied stress caused losses in the mechanical properties of P-110 casing steel specimens. The mechanical properties of casing specimens, resisting external 
forces and corrosion, were reduced by $\mathrm{H}_{2} \mathrm{~S}$ and $\mathrm{CO}_{2}$, which made the casing specimens more susceptible to brittle fracture and failure. At first, hydrogen diffusion and aggregation only occurred at defects. As the hydrogen pressure gradually increased, local plastic deformation occurred when the hydrogen pressure equaled the yield strength. When the hydrogen pressure equaled the atomic force, micro-cracks initiated. Hydrogen was adsorbed onto the metal surface

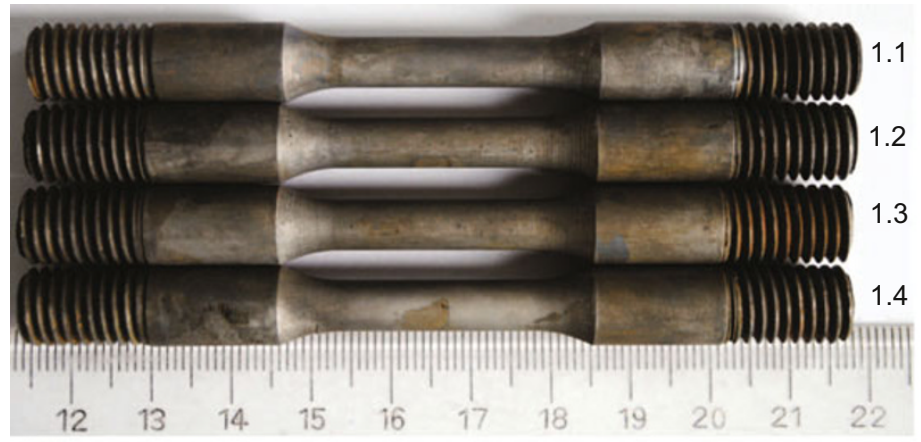

(a) Macro-morphology of specimens from $\mathrm{H}_{2} \mathrm{~S}, \mathrm{CO}_{2}$ corrosion

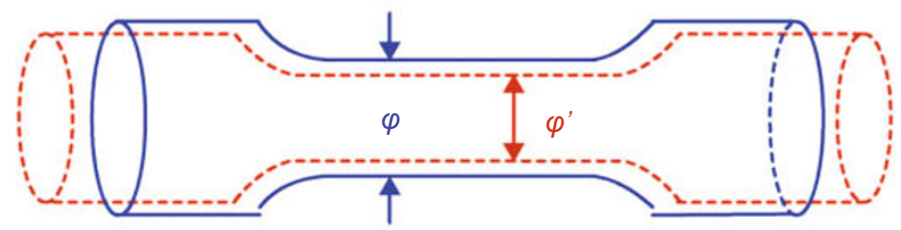

(b) Plastic deformation of specimen induced by $\mathrm{H}_{2} \mathrm{~S}, \mathrm{CO}_{2}$ corrosion

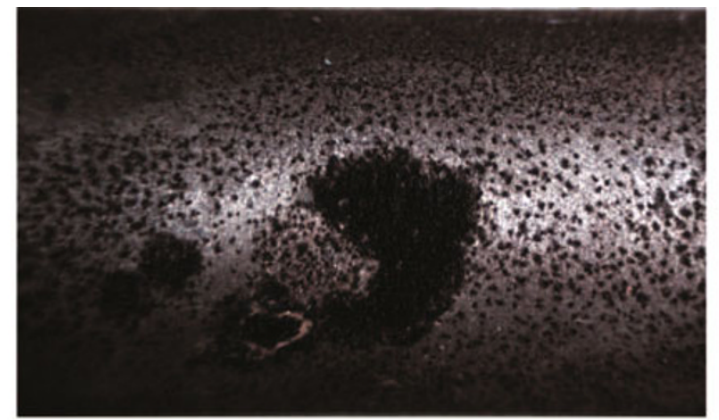

(c) Local surface inregularities induced by $\mathrm{H}_{2} \mathrm{~S}, \mathrm{CO}_{2}$ corrosion

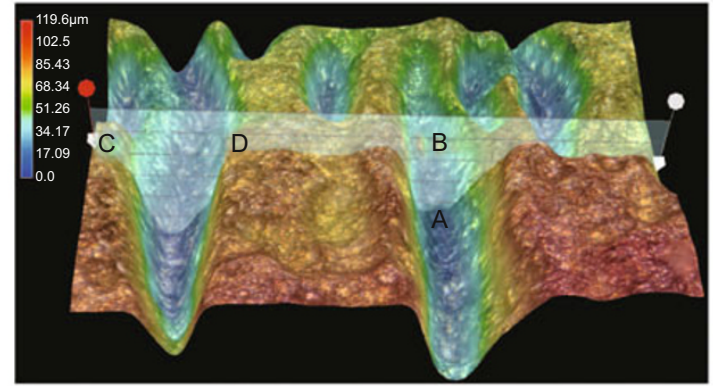

(d) The size and morphology of surface narrow cracks

Fig. 10 Macro-morphology, plastic deformation and surface damage of Specimens C

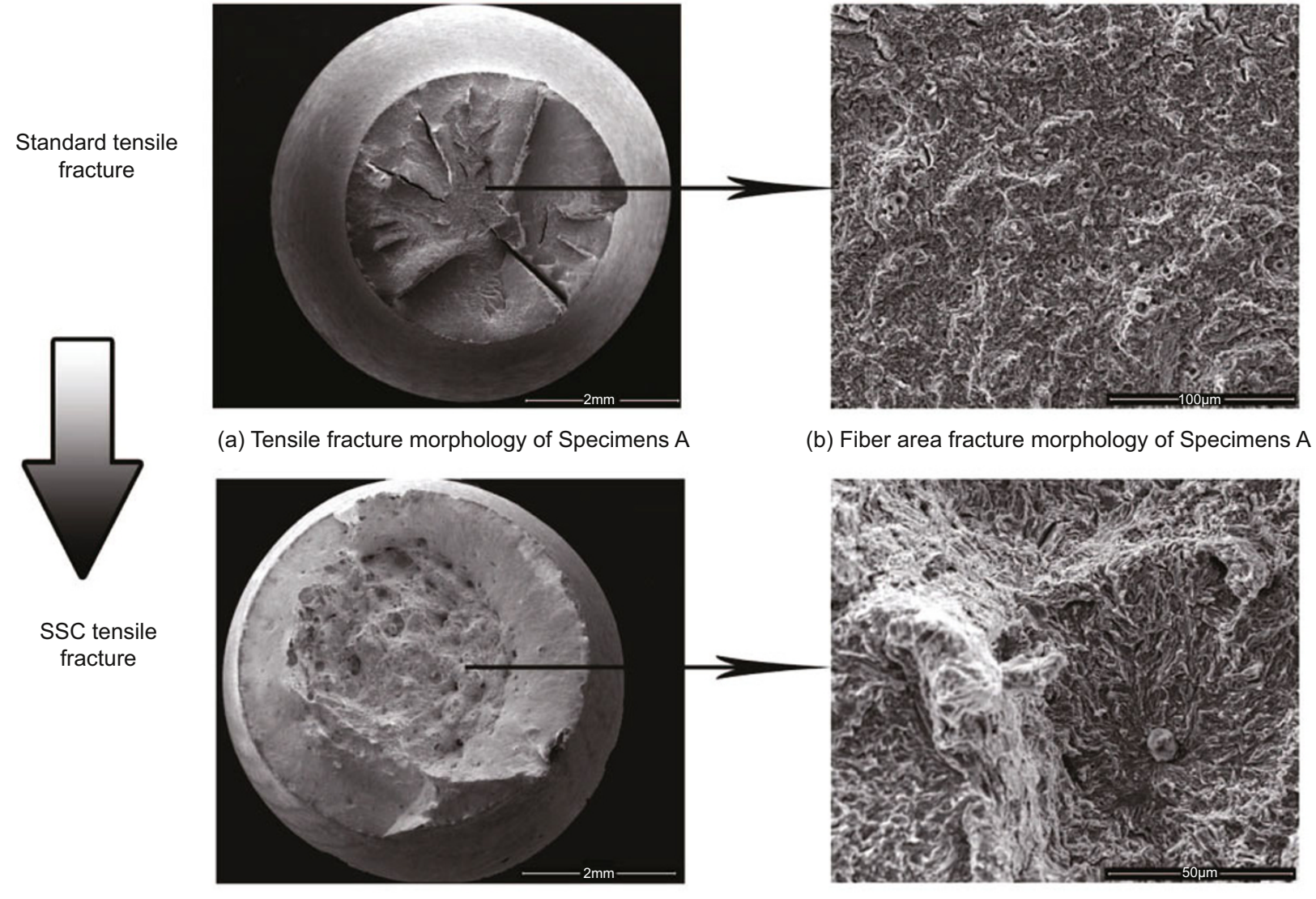

(c) Tensile fracture morphology of Specimens C (d) Fiber area fracture morphology of Specimens C

Fig. 11 Difference in fracture morphology of fibrous zone of specimens A and C 
and further concentrated at defects. This changed the local potential and decreased the surface energy of the metal, resulting in crack initiation and propagation. Eventually, hydrogen permeation enhanced dislocation formation, multiplication and motion, which caused stress concentration and plastic deformation to reach a critical state.

\subsection{Reduction of impact toughness and intergranular fracture}

The impact tests were performed at room temperature on the sub-size specimens before and after exposing them to the sour environments at $60{ }^{\circ} \mathrm{C}$ and $10 \mathrm{MPa}$ and test results are listed in Table 4.

The impact properties of P-110 casing specimens decreased after three-point bend testing conducted in sour environments. Their reductions in impact energy and fracture toughness $\left(K_{\mathrm{IC}}\right)$ were $28 \%$ and $54 \%$, respectively. The values of fracture toughness calculated from Eqs. (3) and
(4) were consistent, indicating that both of these formulas are accurate and reliable. The results also indicate that strain aging phenomena occur in bend specimens, and the notch sensitivity increased after exposure to sour environments at a load of $80 \% \sigma_{\mathrm{s}}$. The impact performance and resistance to external impact forces of P-110 casing specimens decreased due to bending in sour environments $\left(\mathrm{H}_{2} \mathrm{~S}\right.$ and $\left.\mathrm{CO}_{2}\right)$ at high temperature and pressure. These results are consistent with tensile tests performed on Specimens C and D, which were also exposed to sour environments at $60{ }^{\circ} \mathrm{C}$ and $10 \mathrm{MPa}$. The P-110 casing specimens showed strain aging as well as loss in mechanical properties in both the tensile and bend stress corrosion tests. The aging phenomenon was induced by the corrosive effects of the sour environments containing $\mathrm{H}_{2} \mathrm{~S}$ and $\mathrm{CO}_{2}$. The stress, hydrogen damage and microstructural change caused the formation and accumulation of dislocations, and then micro-crack nucleation, and ultimately degradations of the mechanical properties of the specimens.

Table 4 Impact performance of the sub-size impact specimens before and after exposure to sour environments

\begin{tabular}{ccccccc}
\hline $\begin{array}{c}\text { Sub-size } \\
\text { specimen }\end{array}$ & $\begin{array}{c}\text { Impact energy } \\
W_{\mathrm{t}}, \mathrm{J}\end{array}$ & $\begin{array}{c}\text { Yield strength } \\
F_{\mathrm{g},}, \mathrm{kN}\end{array}$ & $\begin{array}{c}\text { Displacement corresponding } \\
\text { to yield strength } S_{\mathrm{gy}}, \mathrm{mm}\end{array}$ & $\begin{array}{c}\text { Crack initiation } \\
\text { energy } W_{\mathrm{m}}, \mathrm{J}\end{array}$ & $\begin{array}{c}\text { Crack propagation } \\
\text { energy } W_{\mathrm{a}}, \mathrm{J}\end{array}$ & $\begin{array}{c}\text { Fracture toughness } \\
K_{\mathrm{IC}}, \mathrm{MPa}^{1 / 2}\end{array}$ \\
\hline $\mathrm{F}$ & 104.5 & 11.62 & 1.21 & 28.8 & 75.7 & 80.3 \\
$\mathrm{E}$ & 74.4 & 10.09 & 1.08 & 19.9 & 54.5 & 36.7 \\
\hline
\end{tabular}

The characteristics of the impact properties of P-110 steel specimens after corrosion tests primarily highlight differences between the load-displacement and energy-displacementcurves. Compared to the curves of Sub-size specimens F without any pretreatment, curves of specimens that underwent SSC testing were offset, resulting in a decrease in the total displacement, as shown in Fig. 12. In addition, the energy consumed by crack formation and crack propagation significantly declined for SSC testing specimens (Sub-size specimens E). These results are explained by tensile and bend stress corrosion tests, 1) cracks were formed more easily, 2) specimens had reduced resistance to external impact forces, 3) specimens had reduced fracture toughness, and 4) fracture and failure occurred more easily. Stress concentration and micro-cracks occurred at the bottom of the V-notch in impact test specimens due to the stress of pre-load up to $80 \% \sigma_{\mathrm{s}}$ and the corrosive test conditions at $60{ }^{\circ} \mathrm{C}, 10 \mathrm{MPa}$, where specimens were submerged in simulated formation water for 168 hours. The notch sensitivity of P-110 casing specimens is shown in Fig. 13.

The dislocation-free zone at the crack tip had a high degree of strain and nonlinear elasticity. In general, when a force $\left(P_{\mathrm{Q}}\right)$ greater than the force of atomic bonding was applied, micro-cracks would nucleate at the dislocation-free zone or at the bottom of the V-notch. For ductile materials, micro-crack nucleation and dislocation sources extended in the plastic zone under constant stress and displacement. In the experiment, this led to micro-cracks becoming micro-voids, which changed the properties of the P-110 casing specimens from strong and tough to weak and fragile during the tensile and bend stress corrosion experiments in sour environments.

After the load imposed on the sub-size specimens

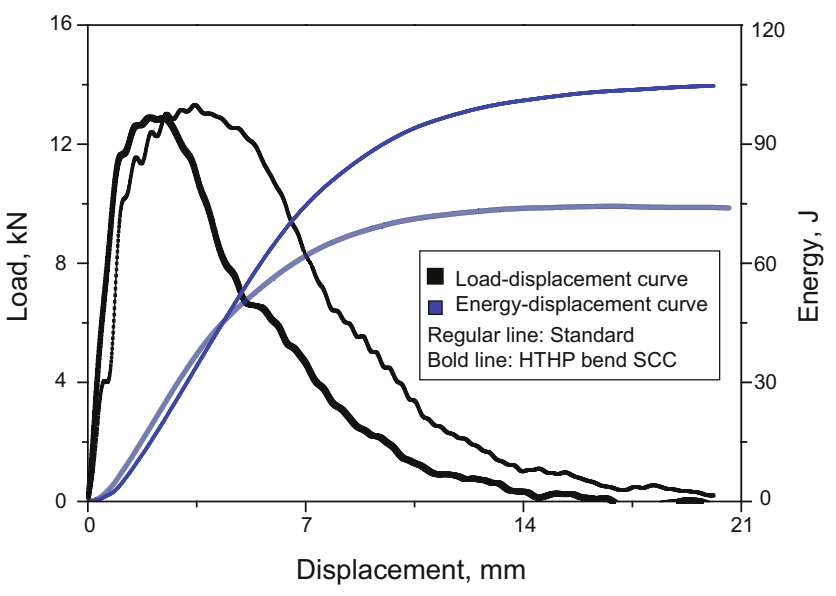

Fig. 12 Displacement-load and displacement-energy curves of sub-size specimens before and after exposure to the sour environment with a bending stress of $85 \% \sigma_{\mathrm{s}}$ for 168 hours

increased up to $85 \% \sigma_{\mathrm{s}}$ in the three-point bending test while other conditions were not changed, the bend specimen showed intergranular cracking at the bottom of the V-notch, as shown in Fig.14. The crack initiated at the root of the $\mathrm{V}$-notch and then experienced nucleation and propagation along the V-notch due to notch sensitivity. Crack growth was accompanied by corrosion effects, and crack propagation and bifurcation occurred at local sites of inhomogeneity in the material. Re-nucleation and further propagation were again prompted by the corrosion effects of $\mathrm{H}_{2} \mathrm{~S}$ and $\mathrm{CO}_{2}$. Because of the crack growth, the sizes of the grains located near cracks were changed. The crack propagated along the 
direction of structural defects, especially at the crack tip. Thus, the constant stress led to corrosion and continuous crack nucleation, which led cracks to continue propagating and developing. Eventually, intergranular cracks were formed due to the sensitivity of the V-notch caused by stress concentration, it changed the metallurgical structure and grain sizes, and also formed stress concentration effects at the crack tip, hydrogen trapping, and hydrogen damage. The crack propagated until the stress at the crack tip reduced to $K_{\mathrm{IC}}$, then crack propagation terminated.

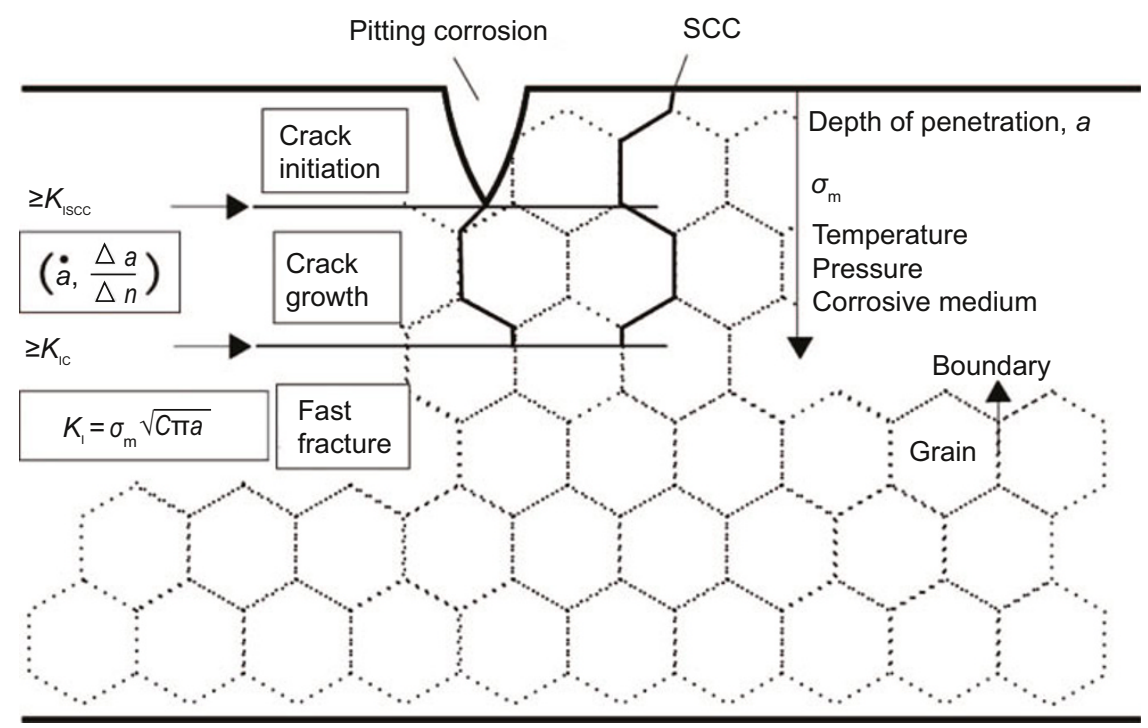

Fig. 13 Mechanism and influencing factors of intergranular cracking caused by hydrogen damage and hydrogen embrittlement

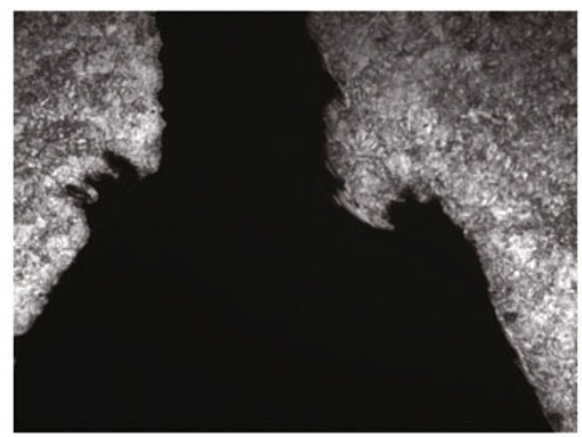

(a) Notch sensitivity crack initiation

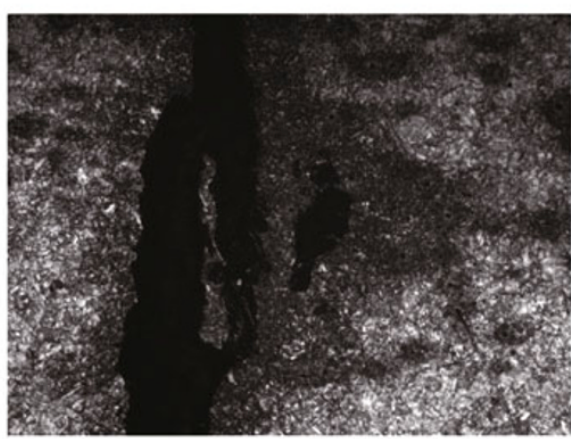

(c) Crack growth and microstructural change
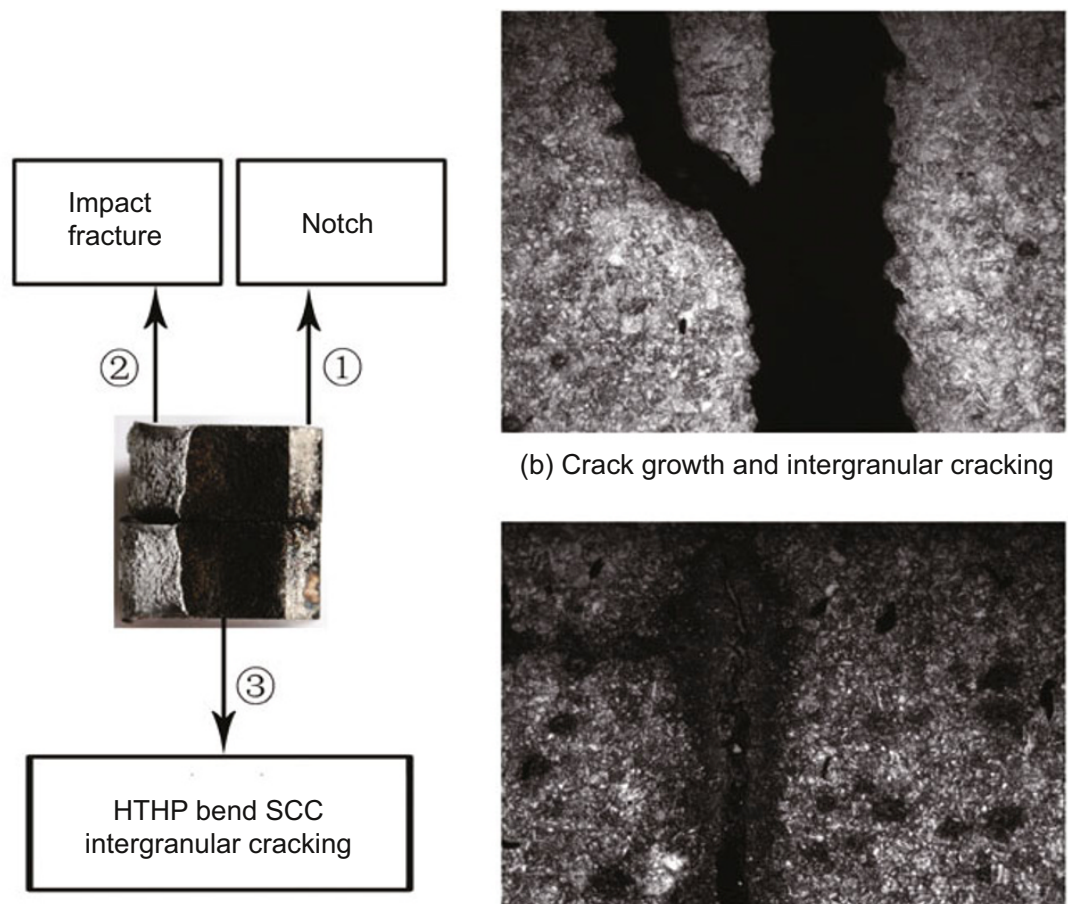

(b) Crack growth and intergranular cracking

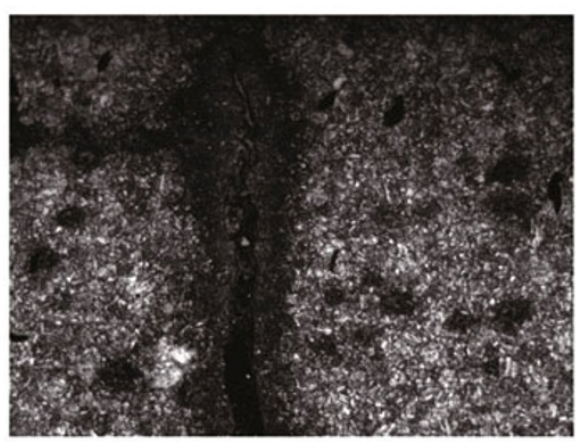

(d) Crack tip and microstructural change

Fig. 14 Notch sensitivity and intergranular cracking caused by sulfide stress cracking in sour environments at $60{ }^{\circ} \mathrm{C}, 10 \mathrm{MPa}(\mathrm{bending}$ stress of $85 \%$ $\sigma_{\mathrm{s}}, 1 \mathrm{MPa} \mathrm{H}_{2} \mathrm{~S}$ partial pressure, $2 \mathrm{MPa} \mathrm{CO}_{2}$ partial pressure, 168 hours)

\section{Conclusions}

1) P-110 casing steel specimens underwent strain aging and were prone to fracture and even failure under a preload of $80 \% \sigma_{\mathrm{s}}$ in a sour environment, which was shown by tensile and impact testing.

2) Surface damage and loss of mechanical properties were found in P-110 casing specimens after exposure to a 
sour environment. Dislocation formation, multiplication and motion were promoted by hydrogen permeation, resulting in the P-110 steel specimens being more prone to crack nucleation and propagation.

3 ) In sour wells, defects and stress concentration on P-110 steel may lead to the acceleration of corrosion and the extension of micro-cracks into micro-voids, thereby changing the casing properties from strong and tough to weak and fragile, making them more susceptible to intergranular fracture.

4) The experimental methods of tensile and impact testing can be used to quantitatively evaluate the mechanical performance of casings in sour environments. Selecting more appropriate materials for casing used in sour environments may help reduce the susceptibility of hydrogen embrittlement on future casing materials.

\section{Acknowledgements}

The authors are thankful for the support of the State Key Laboratory of Oil and Gas Reservoir Geology and Exploitation, Southwest Petroleum University in China, and the National Natural Science Foundation of China (Grant No. 51004084).

\section{References}

Albarran J L, Martinez L and Lopez H F. Effect of heat treatment on the stress corrosion resistance of a microalloyed pipeline steel. Corrosion Science. 1999. 41(6): 1037-1049

American Society for Testing and Materials. ASTM G39-99. Standard practice for preparation and use of bent-beam stress corrosion test specimens. ASTM International. 1999. Philadelphia PA

Carneiro R A, Ratnapuli R C and Lins V F C L. The influence of chemical composition and microstructure of API linepipe steels on hydrogen induced cracking and sulfide stress corrosion cracking. Materials Science and Engineering. 2003. 357 (1): 104-110

Crabtree A and Gavin W. Coiled tubing in sour environments: theory and practice. SPE Drilling \& Completion. 2005. 20(1): 71-80 (paper SPE 89614-PA)

Cravero S, Bravo R, Ernst H. A simplified transient approach for modeling crack growth in DCB specimen testing. Corrosion, 14-18 March 2010, San Antonio TX

Cravero S, Bravo R, Ernst H, et al. Evaluation of testing condition effects of the resistance to sulfide stress cracking. Corrosion, 22-26 March 2009, Atlanta GA

Eliaz N, Shachar A, Tal B, et al. Characteristics of hydrogen embrittlement, stress corrosion cracking and tempered martensite embrittlement in high-strength steels. Engineering Failure Analysis. 2002. 9(2): 167-184

Gelder K V, Erlings J G, Damen J W-M, et al. The stress corrosion cracking of duplex stainless steel in $\mathrm{H}_{2} \mathrm{~S} / \mathrm{CO}_{2} / \mathrm{Cl}^{-}$environments Corrosion Science. 1987. 27(10): 1271-1279

Hay M G. Fitness-for-purpose material testing for sour gas service: an overview. Corrosion. 2001. 57(3): 236-252

Kermani B, Martin J W and Esaklul K A. Materials design strategy: effects of $\mathrm{H}_{2} \mathrm{~S} / \mathrm{CO}_{2}$ corrosion on materials selection. Paper No. 06121, NACE Corrosion Conference, 12-16 March 2006, San Diego Ca.

Mack R D, Filippov A G, Ring L D, et al. In-situ expansion of casing and tubing: effect on mechanical properties and resistance to sulfide stress cracking. Corrosion, 26-31 March 2000, Orlando FI.
Michler T and Naumann J. Hydrogen environment embrittlement of austenitic stainless steels at low temperatures. Hydrogen Energy. 2008. 33(8): 2111-2122

National Association of Corrosion Engineers. NACE TM01772005. Laboratory testing of metals for resistance to sulfide stress cracking and stress corrosion cracking in $\mathrm{H}_{2} \mathrm{~S}$ environments. NACE International. 2005. Houston TX

Nesic S, Cai J Y and Lee K L. A multiphase flow and internal corrosion prediction model for mild steel pipelines. Corrosion, 3-7 April 2005, Houston TX

Otegui J L, Fazzini P G, Massone J, et al. Intergranular susceptibility in failures of high pressure tubes. Pressure Vessels and Piping. 2009. 86 (2): $211-220$

Pal S, Ibrahim R N and Raman R K-S. Studying the effect of sensitization on the threshold stress intensity and crack growth for chloride stress corrosion cracking of austenitic stainless steel using circumferential notch tensile technique. Engineering Fracture Mechanics. 2012. 82(1): 158-171

Ritchie R O, Cedeno M H-C, Zackay V F, et al. Effects of silicon additions and retained austenite on stress corrosion cracking in ultrahigh strength steels. Metallurgical Transactions. 1978. 9(1): 3540

Shimada M, Kokawa H, Wang Z J, et al. Optimization of grain boundary character distribution for intergranular corrosion resistant 304 stainless steel by twin-induced grain boundary engineering. Acta Materialia. 2002. 50(9): 2331-2341

Smith S N and Joosten M W. Corrosion of carbon steel by $\mathrm{H}_{2} \mathrm{~S}$ in $\mathrm{CO}_{2}$ containing oilfield environments. Corrosion, 12-16 March 2006, San Diego Ca.

Srinivasan S and Kane R D. Prediction of corrosivity of $\mathrm{CO}_{2} / \mathrm{H}_{2} \mathrm{~S}$ production environments. Corrosion, 24-29 March 1996, Denver Co.

Srinivasan $\mathrm{S}$ and Tebbal S. Critical factors in predicting $\mathrm{CO}_{2} / \mathrm{H}_{2} \mathrm{~S}$ corrosion in multiphase systems. Corrosion, 22-27 March 1998, San Diego Ca.

Stoll A and Wilkinson A J. Use of a dislocation-based boundary element model to extract crack growth rates from depth distributions of intergranular stress corrosion cracks. Acta Materialia. 2012. 60(13): 5101-5108

Thompson N G, Yunovich M and Dunmire D. Cost of corrosion and corrosion maintenance strategies. Corrosion Reviews. 2007. 25(3): 247-262

Toribio J, Lancha A M and Elices M. Factors influencing stress corrosion cracking of high strength pearlitic steels. Corrosion Science. 1993. 35(1): 521-530

Venegas V, Caleyo F, Baudin T, et al. On the role of crystallographic texture in mitigating hydrogen-induced cracking in pipeline steels. Corrosion Science. 2011. 53(12): 4202-4212

Woodtli J and Kieselbach R. Damage due to hydrogen embrittlement and stress corrosion cracking. Engineering Failure Analysis. 2000. 7(6): 427-450

Zhang L, Zhong W, Yang J, et al. Effects of temperature and partial pressure on $\mathrm{H}_{2} \mathrm{~S} / \mathrm{CO}_{2}$ corrosion of pipeline steel in sour conditions. Corrosion, 13-17 March 2011, Houston TX

Zhao M C and Yang K. Strengthening and improvement of sulfide stress cracking resistance in acicular ferrite pipeline steels by nano-sized carbonitrides. Scripta Materialia. 2005. 52(9): 881-886

Zhao M C, Tang B, Shan Y Y, et al. Role of microstructure on sulfide stress cracking of oil and gas pipeline steels. Chemistry and Materials Science. 2003. 34(9): 1089-1096

Zheng S Q, Li C Y and Chen C F. The accelerated corrosion of elemental sulfur for carbon steel in wet $\mathrm{H}_{2} \mathrm{~S}$ environment. Applied Mechanics and Materials. 2011. 117(1): 999-1002

(Edited by Sun Yanhua) 